\title{
Risk of Chronic Kidney Disease in Non-Obese Individuals with Clustering of Metabolic Factors: A Longitudinal Study
}

\author{
Kunihito Nishikawa ${ }^{1,2}$, Ken Takahashi ${ }^{2}$, Toshio Okutani ${ }^{1}$, Ryoji Yamada ${ }^{1}$, Tsuyoshi Kinaga ${ }^{1}$, \\ Masato Matsumoto ${ }^{1}$ and Masayuki Yamamoto ${ }^{1}$
}

\begin{abstract}
Objective The impact of the clustering of metabolic factors on chronic kidney disease (CKD) in non-obese individuals remains unclear.

Methods We conducted a follow-up study of 23,894 Japanese adults (age, 18-69 years) who continuously received annual health examinations between 2000 and 2011. Obesity, high blood pressure, high triglycerides, low high-density lipoprotein (HDL) cholesterol and high fasting blood sugar were defined as metabolic factors, and CKD was defined as renal dysfunction (estimated glomerular filtration rate: $<60 \mathrm{~mL} / \mathrm{min} / 1.73 \mathrm{~m}^{2}$ ) or proteinuria (dipstick test: $\geq 1+$ ). The association between the clustering of metabolic factors and CKD was assessed based on the presence or absence of obesity using a Cox proportional hazard model.

Results Of 2,867 subjects with $\geq 3$ metabolic factors, 650 (22.7\%) were non-obese. These individuals were older and had higher metabolic risks than their obese counterparts at baseline. Among the entire cohort of 23,894 subjects, 1,764 developed renal dysfunction and 904 developed proteinuria during an average followup period of 7.8 years. The cumulative incidence of renal dysfunction was higher (22.1\% vs. $16.1 \%)$, whereas that of proteinuria was lower $(10.5 \%$ vs. $14.4 \%)$, among the non-obese subjects with $\geq 3$ metabolic factors than the obese subjects with $\geq 3$ metabolic factors after 11 years. The adjusted relative risk (RR) (95\% confidence interval) of renal dysfunction was 1.54 (1.34-1.77) and 1.67 (1.35-2.07) for the obese and nonobese subjects with $\geq 3$ metabolic factors, respectively.

Conclusion Non-obese subjects with $\geq 3$ metabolic factors, who are missed based on the essential criterion of obesity for metabolic syndrome, may have an equal or slightly higher risk of renal dysfunction than obese subjects with $\geq 3$ metabolic factors.
\end{abstract}

Key words: chronic kidney disease, metabolic syndrome, obesity, proteinuria, renal dysfunction

(Intern Med 54: 375-382, 2015)

(DOI: 10.2169/internalmedicine.54.3092)

\section{Introduction}

In 2002, the National Kidney Foundation (NKF) proposed a new definition for chronic kidney disease (CKD) that encompassed a wide range of kidney diseases (1). CKD is not only a precursor of end-stage renal disease (ESRD), but has also been identified as a risk factor for cardiovascular disease (CVD) in the early stage $(2,3)$. The number of patients with ESRD has been increasing worldwide, with diabetic nephropathy recognized as the most significant cause of this increase (3), and hypertension, dyslipidemia and obesity are considered to independently damage the kidneys $(4,5)$. A number of studies have recently focused on the relationship between metabolic syndrome (MS), the clustering of metabolic risk factors within the same individual and CKD (6-15).

The World Health Organization first defined diagnostic criteria for MS in 1999 (16) and, since then, various sets of criteria have been proposed by several institutions. However, differences exist among criteria regarding whether insulin resistance and/or abdominal obesity are essential compo-

${ }^{1}$ Center of Medical Check-up, Shinko Hospital, Shinkokai, Japan and ${ }^{2}$ Department of Environmental Epidemiology, Institute of Industrial Ecological Sciences, University of Occupational and Environmental Health, Japan

Received for publication April 14, 2014; Accepted for publication July 6, 2014

Correspondence to Dr. Kunihito Nishikawa, nishikawa@ shinkohp.or.jp 
nents of MS as well as the components of these parameters and their abnormal values. For example, the National Cholesterol Education Program (NCEP) (17) criteria regard obesity as an MS component, whereas the International Diabetes Federation (IDF) (18) and Japanese criteria (19) include obesity as an essential component. The relative superiority of the NCEP and IDF criteria for predicting CVD remains controversial. According to the use of obesity-based criteria for MS, concerns have been raised over the possibility of overlooking normal-weight individuals with multiple risk factors at high risk of CVD and carotid atherosclerosis (20-26). However, no longitudinal studies have compared the risk of CKD between obese and non-obese individuals with metabolic disorders.

A decreased renal function and proteinuria are the main clinical abnormalities associated with CKD, although these conditions are considered to involve different pathological pathways leading to the development of CKD. Therefore, we compared the incidence of renal dysfunction and proteinuria in obese and non-obese Japanese adults without a history of CVD who exhibited multiple metabolic factors over an 11-year follow-up period.

\section{Materials and Methods}

\section{Subjects and study design}

Our health screening institution conducts health examinations for the employees of the Kobe Steel Group, one of Japan's leading steelmakers, which consists of 12 major factories, 13 local sales offices and 272 small- and medium-sized cooperative firms in Japan. Of the 26,686 workers who annually undergo health examinations, including renal function tests and urinalyses, based on the Industrial Safety and Health Law (27), 23,894 (20,520 men and 3,374 women) were selected as subjects after excluding those with the following conditions at the baseline survey performed between April 2000 and March 2001: 1) a history of coronary heart disease or stroke $(n=504), 2)$ a history of nephro-urological diseases such as kidney or ureteral tumors, nephritis, nephropathy, nephrotic syndrome, pyelonephritis, kidney abscesses or renal failure $(n=99), 3)$ an estimated glomerular filtration rate (eGFR) of $\left.<60 \mathrm{~mL} / \mathrm{min} / 1.73 \mathrm{~m}^{2}(\mathrm{n}=1,515), 4\right)$ proteinuria (dipstick test $\geq 1+)(\mathrm{n}=681)$ and 5) missing data $(n=273)$. Subjects 18-69 years of age (mean: $46.9 \pm 10.2$ years) were followed up for incident CKD on annual health examinations after the baseline survey through March 2012.

\section{Data collection}

1) Information concerning age, sex, smoking status, daily alcohol consumption, exercise habits, walking time to work and history of present and past illnesses was collected via a self-administered questionnaire and checked by a physician at the annual health examinations.

2) Subjects who regularly engaged in manufacturing, mechanical, maintenance or other types of physical work were distinguished as blue-collar workers from white-collar workers. Based on a previous study (28), subjects who engaged in harmful operations associated with the use of lead, organic solvents, silica, beryllium or chromium were considered to be at risk of occupational kidney diseases (none of our subjects were considered to be exposed to cadmium, mercury or arsenic).

3) Body height and weight were measured, and the body mass index (BMI) was calculated as the body weight $(\mathrm{kg})$ divided by the body height squared $\left(\mathrm{m}^{2}\right)$. Blood pressure (BP) was measured in the sitting position after at least five minutes of rest.

4) Blood samples were obtained from the antecubital vein after 10 hours of fasting. The high-density lipoprotein (HDL) cholesterol, triglyceride, fasting blood sugar and serum creatinine ( $\mathrm{SCr}$ ) measurements were commissioned to an outside testing organization (Health Science Research Institute, Yokohama, Japan). The SCr level was measured according to an enzymatic method using an automatic analyzer (Hitachi 7700; Hitachi, Ltd., Tokyo, Japan). The level of urinary protein was examined using a dipstick test (E-UR32; Eiken Chemical Tokyo, Japan).

When obtaining the health records, the identities of the subjects, including their names, were encrypted to protect their privacy. This study was conducted in compliance with the Japanese Ethical Guidelines for Epidemiological Research (29).

\section{Definitions of various metabolic factors}

While waist circumference is included as a component in the NCEP criteria for MS, no data were collected on waist circumference at baseline. Therefore, we substituted BMI for this measurement. A BMI of $\geq 25.0 \mathrm{~kg} / \mathrm{m}^{2}$ was used as the criterion for obesity; this BMI level has previously been shown to correspond well with the Japanese criterion for a high visceral fat area of $\geq 100 \mathrm{~cm}^{2}$, which defines central obesity $(19,30)$, and is currently proposed as a cut-off value for the diagnosis of obesity in Asians (31). Based on the NCEP criteria (17), a subject's condition was considered to reflect metabolic factor clustering if he/she had three or more of the following five metabolic factors: obesity (BMI $\left.\geq 25.0 \mathrm{~kg} / \mathrm{m}^{2}\right)$, high $\mathrm{BP}(\geq 130 / 85 \mathrm{~mm} \mathrm{Hg})$, high triglycerides $(\geq 150 \mathrm{mg} / \mathrm{dL})$, low HDL cholesterol $(<40 \mathrm{mg} / \mathrm{dL}$ in men and $<50 \mathrm{mg} / \mathrm{dL}$ in women) and high fasting blood sugar ( $\geq$ $110 \mathrm{mg} / \mathrm{dL}$ ). The subjects were categorized into three groups based on the presence of metabolic factor clustering and obesity as follows: 1) 0-2 metabolic factors, including subjects with $<3$ metabolic factors; 2) $\geq 3$ metabolic factors/obesity, including obese subjects with $\geq 2$ other metabolic factors; and 3) $\geq 3$ metabolic factors/no obesity, including normal-weight subjects with $\geq 3$ other metabolic factors.

\section{Definition of CKD}

Based on the NKF guidelines (1), CKD was defined as renal dysfunction or proteinuria. Renal dysfunction was considered to be present if the eGFR was $<60 \mathrm{~mL} / \mathrm{min} / 1.73 \mathrm{~m}^{2}$, 
Table 1. Baseline Characteristics of Subjects Based on the Presence of Metabolic Factor Clustering

\begin{tabular}{|c|c|c|c|}
\hline & $\begin{array}{c}0-2 \text { metabolic } \\
\text { factors }^{\mathrm{a}} \\
\mathrm{n}=21,027\end{array}$ & $\begin{array}{c}\geq 3 \text { metabolic } \\
\text { factors }^{\mathrm{a}} \\
\mathrm{n}=2,867\end{array}$ & $\mathrm{p}$ value $\mathrm{b}^{\mathrm{b}}$ \\
\hline Age (years) & $46.6 \pm 10.3$ & $48.9 \pm 8.6$ & $<0.001$ \\
\hline Male & $17,819(84.7 \%)$ & $2,701(94.2 \%)$ & $<0.001$ \\
\hline \multicolumn{4}{|l|}{ Metabolic factors } \\
\hline Body mass index $\left(\mathrm{kg} / \mathrm{m}^{2}\right)$ & $22.4 \pm 2.7$ & $26.3 \pm 2.8$ & $<0.001$ \\
\hline Systolic BP (mm Hg) & $121.8 \pm 15.4$ & $137.0 \pm 14.5$ & $<0.001$ \\
\hline Diastolic BP (mm Hg) & $74.5 \pm 10.7$ & $84.3 \pm 9.9$ & $<0.001$ \\
\hline Triglycerides (mg/dL) & $95.3 \pm 65.4$ & $210.8 \pm 142.5$ & $<0.001$ \\
\hline HDL cholesterol (mg/dL) & $59.3 \pm 14.8$ & $45.3 \pm 12.2$ & $<0.001$ \\
\hline Fasting blood sugar (mg/dL) & $96.3 \pm 14.9$ & $111.2 \pm 27.2$ & $<0.001$ \\
\hline Smoking status & & & 0.029 \\
\hline Never & $10,261(48.8 \%)$ & $1,244(43.4 \%)$ & \\
\hline Past & $1,046(5.0 \%)$ & $183(6.4 \%)$ & \\
\hline$<20$ cigarettes/day & $6,112(29.1 \%)$ & $750(26.2 \%)$ & \\
\hline$\geq 20$ cigarettes/day & $3,608(17.2 \%)$ & $690(24.1 \%)$ & \\
\hline Alcohol (ethanol) consumption & & & 0.126 \\
\hline $0 \mathrm{~g} /$ day & $5,190(24.7 \%)$ & $638(22.3 \%)$ & \\
\hline $1-19 \mathrm{~g} /$ day & $7,617(36.2 \%)$ & $929(32.4 \%)$ & \\
\hline $20-39 \mathrm{~g} /$ day & $4,382(20.8 \%)$ & $625(21.8 \%)$ & \\
\hline $40-59 \mathrm{~g} /$ day & $3,125(14.9 \%)$ & $482(16.8 \%)$ & \\
\hline$\geq 60 \mathrm{~g} /$ day & $713(3.4 \%)$ & $193(6.7 \%)$ & \\
\hline Exercise habits & & & 0.099 \\
\hline 0 days/week & $11,757(55.9 \%)$ & $1,593(55.6 \%)$ & \\
\hline 1-2 days/week & $6,823(32.4 \%)$ & $914(31.9 \%)$ & \\
\hline 3-4 days/week & $1,287(6.1 \%)$ & $198(6.9 \%)$ & \\
\hline$\geq 5$ days/week & $1,160(5.5 \%)$ & $162(5.7 \%)$ & \\
\hline Walking time in commutation & & & 0.061 \\
\hline$<30 \mathrm{~min} /$ day & $16,502(78.5 \%)$ & $2,269(79.1 \%)$ & \\
\hline $30-59 \mathrm{~min} /$ day & $3,725(17.7 \%)$ & $491(17.1 \%)$ & \\
\hline$\geq 60 \mathrm{~min} /$ day & $800(3.8 \%)$ & $107(3.7 \%)$ & \\
\hline Blue-collar worker & $6,937(33.0 \%)$ & $1,022(35.6 \%)$ & 0.591 \\
\hline \multicolumn{4}{|l|}{ Occupational exposure } \\
\hline Lead & $141(0.7 \%)$ & $16(0.6 \%)$ & 0.447 \\
\hline Organic solvent & $926(4.4 \%)$ & $114(4.0 \%)$ & 0.562 \\
\hline Silica & $1,843(8.8 \%)$ & $282(9.8 \%)$ & 0.925 \\
\hline Beryllium & $37(0.2 \%)$ & $7(0.2 \%)$ & 0.551 \\
\hline Chromium & $128(0.6 \%)$ & $15(0.5 \%)$ & 0.437 \\
\hline
\end{tabular}

Data are expressed as mean \pm SD or number (percentage).

BP: blood pressure, HDL: high-density lipoprotein.

${ }^{a}$ We defined obesity, high blood pressure, high triglycerides, low HDL cholesterol and high fasting

blood sugar as metabolic factors (see the Materials and Methods section).

${ }^{b} \mathrm{p}$ values were obtained by an analysis of co-variance or the $\chi^{2}$-test adjusted for age and sex.

and proteinuria was regarded as positive for dipstick urinary protein scores of $\geq 1+$. The eGFR was calculated based on the SCr level and age using the following estimation equation derived from inulin clearance data in a Japanese population (32):

eGFR $\left(\mathrm{mL} / \mathrm{min} / 1.73 \mathrm{~m}^{2}\right)=194 \times \mathrm{SCr}^{-1.094} \times \operatorname{Age}^{-0.287}(\times 0.739$ for women)

Traditional CVD risk factors are considered to predict both renal dysfunction and proteinuria. However, renal dysfunction and proteinuria are independent, but coexistent, manifestations of different pathologies associated with renal and cardiovascular risks. Hence, renal dysfunction and proteinuria were analyzed separately in this study.

\section{Statistical analysis}

The baseline clinical characteristics of the groups stratified according to metabolic factor clustering and obesity were compared using an analysis of co-variance or the $\chi^{2}$ test. After the follow-up period of 11 years, the cumulative incidence of CKD was calculated for each group based on the Kaplan-Meier Method. The adjusted relative risk (RR) of CKD for each group was evaluated using a Cox proportional hazard model adjusted for age, sex, lifestyle, type of work and occupational exposure. We further adjusted for other metabolic factors when calculating the RR for each metabolic factor. A $p$ value of $<0.05$ was considered to be statistically significant. All analyses were performed using the PASW ver18.0J software package (SPSS, Chicago, IL, USA).

\section{Results}

\section{Baseline characteristics of the obese and non-obese groups according to the presence of metabolic fac- tor clustering}

As shown in Table 1, the prevalence of $\geq 3$ metabolic factors was $12.0 \%(n=2,867)$ among our subjects at baseline. 
Table 2. Baseline Characteristics of Subjects with Metabolic Factor Clustering Based on the Presence of Obesity

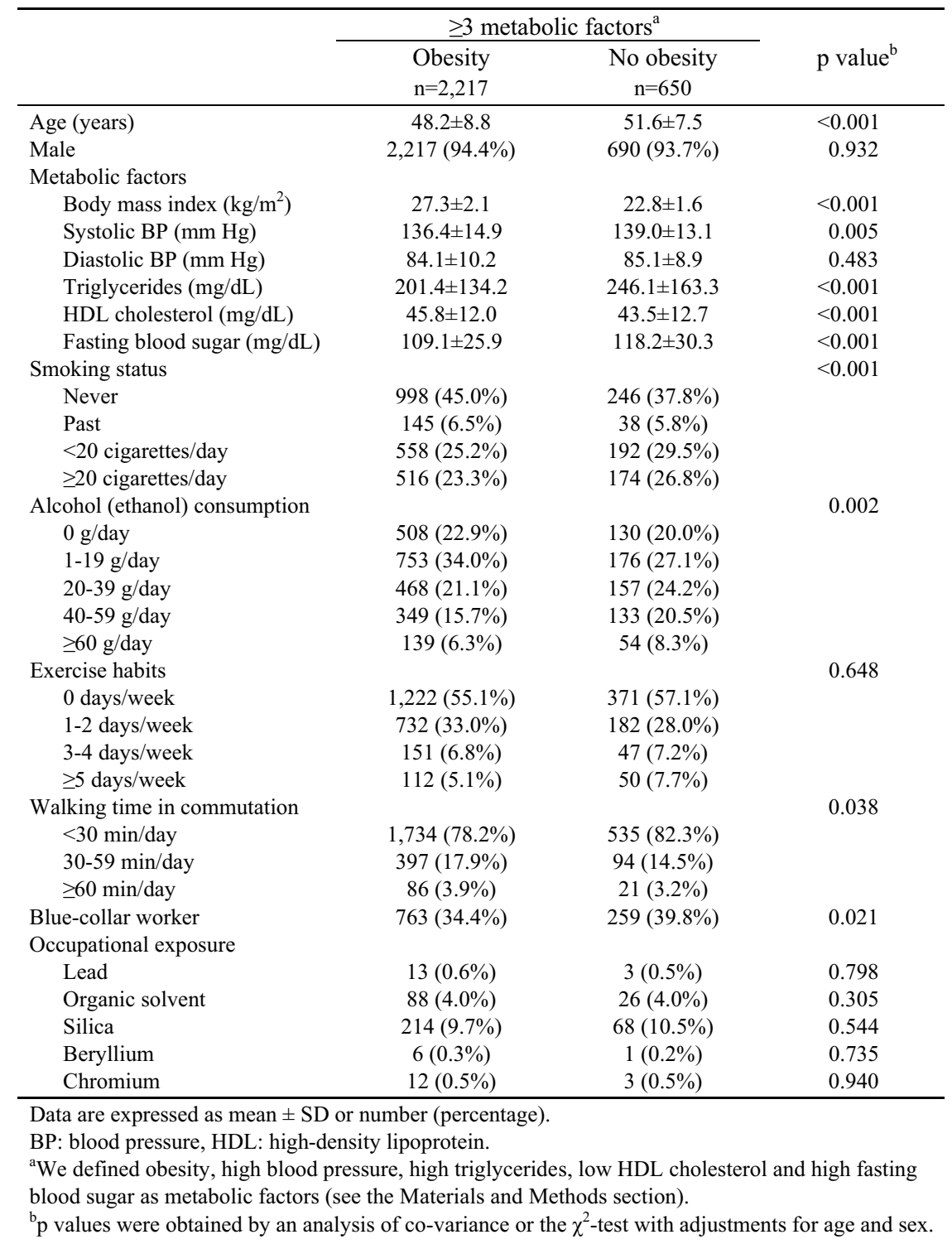

Significant differences were observed in age, sex, all metabolic factors and the smoking status between the two groups.

\section{Baseline characteristics of the obese and non-obese groups with metabolic factor clustering}

As shown in Table 2, $650(22.7 \%)$ of the 2,867 subjects with $\geq 3$ metabolic factors were not obese. The non-obese subjects with $\geq 3$ metabolic factors were 3.4 years older and had higher mean systolic BP, triglyceride and fasting blood sugar values, but lower HDL cholesterol levels, than the obese subjects with $\geq 3$ metabolic factors $(p<0.05)$. In the $\geq 3$ metabolic factors/no obesity group, the incidence of current smoking (56.3\%), high alcohol (ethanol) consumption $(\geq 20$ g/day) $(53.0 \%)$, lack of walking time during the day $(<30$ min/day) (82.3\%) and blue-collar workers (39.8\%) was higher than that observed in the $\geq 3$ metabolic factors/obesity group $(\mathrm{p}<0.05)$.

\section{Cumulative incidence of CKD according to the pres- ence of metabolic factor clustering and obesity}

The cumulative observation period was 185,860 personyears. During the mean observation period of 7.8 \pm 3.6 years, 1,764 subjects newly developed renal dysfunction and 904 subjects newly developed proteinuria. As shown in Figure, the cumulative incidence of renal dysfunction after 11 years was highest at $22.1 \%$ for $\geq 3$ metabolic factors/no obesity, followed by $16.1 \%$ for $\geq 3$ metabolic factors/obesity and $9.7 \%$ for $0-2$ metabolic factors. Meanwhile, the cumulative incidence of proteinuria was lower in the $\geq 3$ metabolic factors/no obesity group $(10.5 \%)$ than in the $\geq 3$ metabolic factors/obesity group (14.4\%).

\section{Adjusted RR of CKD according to the presence of metabolic factor clustering and obesity}

As demonstrated in Table 3, the RR (95\% confidence interval) of renal dysfunction and proteinuria for $\geq 3$ metabolic 


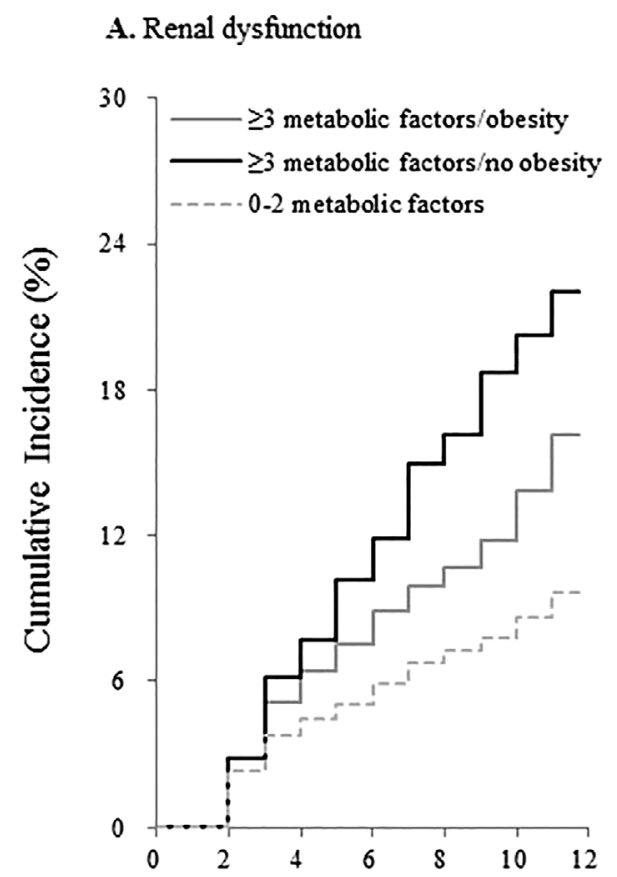

B. Proteinuria

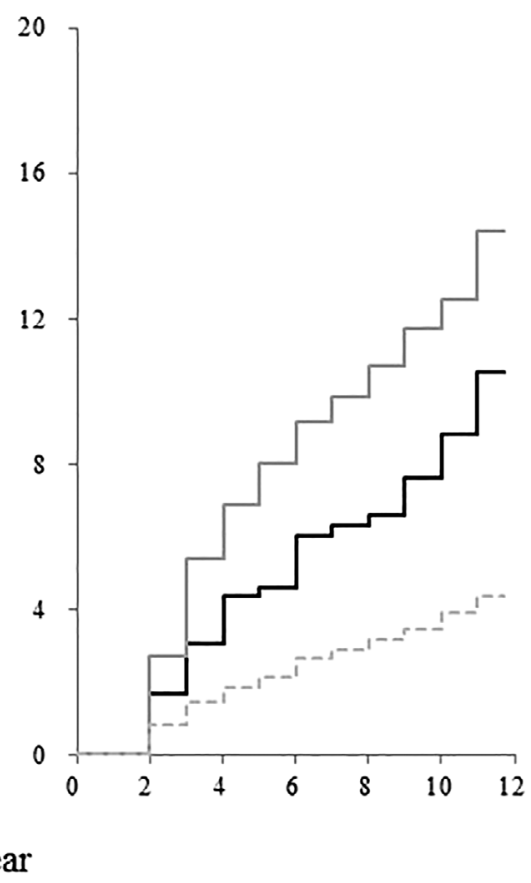

Figure. Cumulative incidence of renal dysfunction and proteinuria according to the presence of metabolic factor clustering and obesity. We defined obesity, high blood pressure, high triglycerides, low HDL cholesterol and high fasting blood sugar as metabolic factors (see the Materials and Methods section).

Table 3. Multivariate-adjusted Relative Risks for Renal Dysfunction and Proteinuria Based on the Presence of Metabolic Factor Clustering and Obesity

\begin{tabular}{|c|c|c|c|c|c|c|c|c|c|c|}
\hline \multirow[b]{3}{*}{ 0-2 Metabolic factors ${ }^{\mathrm{b}}$} & \multicolumn{5}{|c|}{ Renal dysfunction } & \multicolumn{5}{|c|}{ Proteinuria } \\
\hline & \multirow{2}{*}{$\begin{array}{c}\text { case } \\
1,439\end{array}$} & \multirow{2}{*}{$\begin{array}{c}\text { person-years } \\
158,666\end{array}$} & \multicolumn{2}{|c|}{$\mathrm{RR}^{\mathrm{a}}(95 \% \mathrm{CI})$} & \multirow{2}{*}{$\frac{\mathrm{p} \text { value }}{-}$} & \multirow{2}{*}{$\begin{array}{r}\text { case } \\
644\end{array}$} & \multirow{2}{*}{$\begin{array}{c}\text { person-years } \\
161,145\end{array}$} & \multicolumn{2}{|c|}{$\mathrm{RR}^{\mathrm{a}}(95 \% \mathrm{CI})$} & \multirow{2}{*}{$\frac{\mathrm{p} \text { value }}{-}$} \\
\hline & & & 1 & - & & & & 1 & - & \\
\hline$\geq 3$ Metabolic factors ${ }^{b}$ & 325 & 20,910 & 1.57 & $(1.39-1.77)$ & $<0.001$ & 261 & 20,882 & 2.94 & $(2.54-3.40)$ & $<0.001$ \\
\hline Obesity & 236 & 16,408 & 1.54 & $(1.34-1.77)$ & $<0.001$ & 219 & 16,333 & 3.19 & $(2.74-3.73)$ & $<0.001$ \\
\hline No obesity & 89 & 4,502 & 1.67 & $(1.35-2.07)$ & $<0.001$ & 42 & 4,549 & 2.08 & $(1.52-2.85)$ & $<0.001$ \\
\hline
\end{tabular}

CI: confidence interval, RR: relative risk

${ }^{a}$ Multivariate RRs were adjusted for age, sex, smoking status, alcohol consumption, exercise habits, walking time in commutation, type of work and occupational exposure.

${ }^{\mathrm{b}}$ We defined obesity, high blood pressure, high triglycerides, low HDL cholesterol and high fasting blood sugar as metabolic factors (see the Materials and Methods section).

factors was 1.57 (1.39-1.77) and $2.94(2.54-3.40)$, respectively. The RR of renal dysfunction was 1.67 (1.35-2.07) for $\geq 3$ metabolic factors/no obesity, which was higher than that for $\geq 3$ metabolic factors/obesity. However, the RR of proteinuria was 2.08 (1.52-2.85) for $\geq 3$ metabolic factors/no obesity, which was lower than that for $\geq 3$ metabolic factors/obesity and opposite to the results obtained for renal dysfunction.

\section{Adjusted RR of CKD according to five metabolic factors}

As indicated in Table 4, high triglycerides, high BP, obesity and low HDL cholesterol significantly increased the RR of renal dysfunction. On the other hand, high fasting blood sugar, obesity, high BP and high triglycerides significantly increased the RR of proteinuria.

\section{Discussion}

Insulin resistance and abdominal obesity are considered to be fundamental pathogenetic factors for MS; however, the exact mechanisms underlying the development of MS have not yet been established and various criteria for the condition have been proposed. Consequently, the same individual may be diagnosed with MS according to some sets of criteria, but not others. For example, non-obese MS, a seemingly 
Table 4. Multivariate-adjusted Relative Risks for Renal Dysfunction and Proteinuria Based on Individual Metabolic Factors

\begin{tabular}{|c|c|c|c|c|}
\hline & \multicolumn{2}{|c|}{ Renal dysfunction } & \multicolumn{2}{|c|}{ Proteinuria } \\
\hline & $\mathrm{RR}^{\mathrm{a}}(95 \% \mathrm{CI})$ & $p$ value & $\mathrm{RR}^{\mathrm{a}}(95 \% \mathrm{CI})$ & $\mathrm{p}$ value \\
\hline Obesity & $1.18(1.06-1.31)$ & 0.003 & $1.75(1.52-2.02)$ & $<0.001$ \\
\hline High BP & $1.28(1.16-1.41)$ & $<0.001$ & $1.68(1.46-1.93)$ & $<0.001$ \\
\hline High triglycerides & $1.31(1.18-1.46)$ & $<0.001$ & $1.44(1.24-1.66)$ & $<0.001$ \\
\hline Low HDL cholesterol & $1.17(1.01-1.35)$ & 0.032 & $1.19(0.98-1.44)$ & 0.079 \\
\hline High fasting blood sugar & $0.91(0.80-1.05)$ & 0.193 & $2.18(1.87-2.55)$ & $<0.001$ \\
\hline
\end{tabular}

BP: blood pressure, CI: confidence interval, HDL: high-density lipoprotein, RR: relative risk

${ }^{a}$ Multivariate RRs were adjusted for age, sex, smoking status, alcohol consumption, exercise habits,

walking time in commutation, type of work, occupational exposure and other metabolic factors listed in this table.

healthy condition satisfying the NCEP criteria, but not obesity-based criteria, has been reported to be a precursor to type 2 diabetes and CVD (33). In recent years, the risk of CVD has been reported to be higher for non-obese MS patients than for obese MS patients $(20,24,25)$. However, the risk of CKD in these individuals remains unclear.

The present results showed an overall increased risk of both renal dysfunction and proteinuria in subjects with metabolic factor clustering, regardless of obesity. We also found that the risk of renal dysfunction in the non-obese subjects with metabolic factor clustering was similar to that observed in the obese subjects with metabolic factor clustering. This is clinically relevant issue because non-obese individuals are often considered to be at low risk and managed accordingly. Chen et al. first suggested the presence of a strong relationship between MS and CKD in 2004 (12). However, recent studies taking the effects of hypertension and diabetes into consideration have reported results that both support $(7,9-11)$ and reject $(14,15)$ this relationship. Furthermore, a universal consensus has not been reached as to whether MS itself is a risk factor for CKD or if individual risk factors, such as hypertension and diabetes, are involved. Our additional analyses of adults $(n=18,077)$ conducted after excluding those with hypertension, diabetes or treated dyslipidemia at baseline led to similar results to those obtained in the analyses of our subjects performed without excluding such individuals (data not shown).

In the present study, the percentage of non-obese subjects was $22.7 \%(650 / 2,867)$ among our subjects with metabolic factor clustering. Previous studies have reported that the proportion of non-obese individuals among those with MS diagnosed according to the NCEP criteria is 9.7-18.9\% in Europeans $(23,34), 7.6-35.6 \%$ in Asians except for Japanese $(8,10,24,35,36), 25.4-33.6 \%$ in Japanese $(20,22)$ and $31.3-32.6 \%$ in Asians with type 2 diabetes $(6,25)$. The median of these values is higher among Asians than Europeans $(32.5 \%$ vs. $14.3 \%)$. Therefore, the prevalence of metabolic factor clustering without obesity should not be disregarded, especially in Asians, who are known to have a relatively lower prevalence of obesity than Caucasians.

Although previous studies have compared the superiority of the NCEP and IDF criteria for predicting CVD, those concerning CKD have been limited. In French men, MS diagnosed based on the IDF criteria has been shown to be associated with an elevated risk of albuminuria, whereas that diagnosed according to the NCEP criteria has not (7). In Taiwanese subjects, MS diagnosed in accordance with both criteria significantly increases the risk of CKD; this risk is slightly higher for IDF-defined MS (10). Conversely, in Thai workers and Chinese diabetic patients, NCEP-defined MS is correlated with renal dysfunction, while IDF-defined MS is not $(6,13)$. The relationship between non-obese MS per se and renal dysfunction has been evaluated cross-sectionally in patients with type 2 diabetes (6), although it remains poorly understood in healthy populations.

In the present analysis, the RR of proteinuria was higher for metabolic factor clustering with obesity than that without. One possible explanation for this result is that the effects exerted by several metabolic factors on the kidneys are not equal. In accordance with the findings of a previous meta-analysis (37), the effects of five metabolic factors on renal dysfunction and proteinuria also varied in our study. In particular, obesity had the second highest RR for proteinuria among all metabolic factors examined; this value was higher than that for renal dysfunction $(1.75 ; \mathrm{p}<0.001$ vs. 1.18 ; $\mathrm{p}=$ 0.003 ). Yamagata et al. reported that obesity was found to be an independent risk factor for proteinuria, but not renal dysfunction, during a 10-year follow-up period (4). Another study showed that the risk of proteinuria increases progressively in association with elevation of BMI (5). Obesity has also been shown to result in an increase in the renal plasma flow and glomerular filtration rate, whereas weight reduction decreases urinary protein excretion due to improvements in these pathological abnormalities (38). These phenomena likely contributed to the current results.

In contrast, the RR of renal dysfunction was higher for metabolic factor clustering without, than with, obesity in the present study. Possible reasons for these results are as follows. First, although obesity is a known risk factor for proteinuria $(4,5)$, its effects on the development of renal dysfunction remain controversial. Some studies have found no significant relationships between obesity and renal dysfunc- 
tion $(4,11,13,14)$. Second, our non-obese subjects with metabolic factor clustering were older and had more exacerbated metabolic abnormalities, as observed in other studies $(35,36)$. Third, unfavorable lifestyle factors and type of work may have also played an important role in the development of metabolic disorders in our subjects. These factors may have provided the basis for non-obese MS and enhanced the risk of renal dysfunction in these individuals. Our additional evaluations indicated that the non-obese subjects with $\geq 3$ metabolic factors had a higher mean eGFR (76.9 vs. $74.7 \mathrm{~mL} / \mathrm{min} / 1.73 \mathrm{~m}^{2}$ ) at baseline, although a higher RR for renal dysfunction, even after adjusting for confounding factors, including baseline eGFR, than the obese subjects with $\geq 3$ metabolic factors (data not shown).

Non-obese MS is considered to be characterized by body composition and body fat distribution abnormalities (elevation of the visceral fat to subcutaneous fat ratio) as well as decreased insulin sensitivity, even among those with lower BMI values (33). Whether obesity is an essential factor for the basis of MS, or the clustering of the risk factors is more important, remains unclear, which has caused controversy, both in Japan (39) and abroad. Obesity is widely recognized to be a fundamental risk factor for lifestyle-related diseases, and the inclusion of obesity as a criterion for MS may be reasonable from the viewpoint of the need for intensive intervention in obese individuals. In order to prevent increases in the number of patients with lifestyle-related diseases and CVD, an annual health check-up program with a particular focus on the diagnosis of MS according to obesity-based criteria was initiated in Japan in 2008. However, the present study showed that such criteria may fail to identify nonobese individuals with multiple metabolic factors at increased risk of renal dysfunction. Therefore, the exclusion of this high-risk group from targets of lifestyle modification, medical treatment and follow-up may be clinically undesirable.

This study is associated with the following limitations. First, we used the BMI as a substitute for waist circumference in order to diagnose MS, which may have led to underestimation of the effects of obesity on CKD. Second, a reduced eGFR and dipstick proteinuria, used as the endpoints of CKD in this study, may be less accurate for diagnosing CKD. However, the equation used to estimate the GFR in this study has been reported to be more precise than other equations or the SCr level (32). Measurements of the eGFR and dipstick urinalyses are also important indices of renal disorders that are widely used in clinical practice and mass health examinations in Japan. Third, the healthy worker effect may have influenced our findings; therefore, our results may not be easily generalized. However, obtaining results based on periodic health examinations obligated by law rather than voluntary assessments renders selection bias less probable.

In conclusion, the clustering of metabolic factors, irrespective of obesity, is suggested to be an independent risk factor for renal dysfunction and proteinuria in Japanese adults. In the present study, approximately $20 \%$ of subjects with metabolic factor clustering were not obese and had an equal or somewhat higher risk of renal dysfunction than obese patients with metabolic factor clustering.

The authors state that they have no Conflict of Interest (COI).

\section{Financial Support}

This work was supported by a research grant from the Hyogo Prefecture Medical Association, Japan (Grant No. MRF-H-0912).

\section{References}

1. The National Kidney Foundation Kidney Disease Outcomes Quality Initiative (NKF-K/DOQI). K/DOQI clinical practice guidelines for chronic kidney disease: evaluation, classification, and stratification. Am J Kidney Dis 39 (2 Suppl 1): S1-S266, 2002.

2. Go AS, Chertow GM, Fan D, McCulloch CE, Hsu CY. Chronic kidney disease and the risks of death, cardiovascular events, and hospitalization. N Engl J Med 351: 1296-1305, 2004.

3. Levey AS, de Jong PE, Coresh J, et al. The definition, classification, and prognosis of chronic kidney disease: a KDIGO Controversies Conference report. Kidney Int 80: 17-28, 2011.

4. Yamagata K, Ishida K, Sairenchi T, et al. Risk factors for chronic kidney disease in a community-based population: a 10-year follow-up study. Kidney Int 71: 159-166, 2007.

5. Tozawa M, Iseki K, Iseki C, Oshiro S, Ikemiya Y, Takishita S. Influence of smoking and obesity on the development of proteinuria. Kidney Int 62: 956-962, 2002.

6. Luk AO, Ma RC, So WY, et al. The NCEP-ATPIII but not the IDF criteria for the metabolic syndrome identify Type 2 diabetic patients at increased risk of chronic kidney disease. Diabet Med 25: 1419-1425, 2008.

7. Bonnet F, Marre M, Halimi JM, et al. Waist circumference and the metabolic syndrome predict the development of elevated albuminuria in non-diabetic subjects: the DESIR Study. J Hypertens 24: 1157-1163, 2006.

8. Lin CC, Liu CS, Li TC, Chen CC, Li CI, Lin WY. Microalbuminuria and the metabolic syndrome and its components in the Chinese population. Eur J Clin Invest 37: 783-790, 2007.

9. Watanabe H, Obata H, Watanabe T, Sasaki S, Nagai K, Aizawa Y. Metabolic syndrome and risk of development of chronic kidney disease: the Niigata preventive medicine study. Diabetes Metab Res Rev 26: 26-32, 2010.

10. Sun F, Tao Q, Zhan S. Metabolic syndrome and the development of chronic kidney disease among 118924 non-diabetic Taiwanese in a retrospective cohort. Nephrology (Carlton) 15: 84-92, 2010.

11. Kurella M, Lo JC, Chertow GM. Metabolic syndrome and the risk for chronic kidney disease among nondiabetic adults. J Am Soc Nephrol 16: 2134-2140, 2005.

12. Chen J, Muntner P, Hamm LL, et al. The metabolic syndrome and chronic kidney disease in U.S. adults. Ann Intern Med 140: 167174, 2004.

13. Kitiyakara C, Yamwong S, Cheepudomwit S, et al. The metabolic syndrome and chronic kidney disease in a Southeast Asian cohort. Kidney Int 71: 693-700, 2007.

14. Rashidi A, Ghanbarian A, Azizi F. Are patients who have metabolic syndrome without diabetes at risk for developing chronic kidney disease? Evidence based on data from a large cohort screening population. Clin J Am Soc Nephrol 2: 976-983, 2007.

15. Lucove J, Vupputuri S, Heiss G, et al. Metabolic syndrome and the development of CKD in American Indians: the Strong Heart Study. Am J Kidney Dis 51: 21-28, 2008.

16. Alberti KG, Zimmet PZ. Definition, diagnosis and classification of 
diabetes mellitus and its complications. Part 1: diagnosis and classification of diabetes mellitus provisional report of a WHO consultation. Diabet Med 15: 539-553, 1998.

17. The National Cholesterol Education Program (NCEP). Executive summary of the third report of the NCEP expert panel on detection, evaluation, and treatment of high blood cholesterol in adults (Adult Treatment Panel III). JAMA 285: 2486-2497, 2001.

18. Alberti KG, Zimmet $P$, Shaw J. Metabolic syndrome--a new world-wide definition. A Consensus Statement from the International Diabetes Federation. Diabet Med 23: 469-480, 2006.

19. Matsuzawa Y. Metabolic syndrome--definition and diagnostic criteria in Japan. J Atheroscler Thromb 12: 301, 2005.

20. Kadota A, Hozawa A, Okamura T, et al. Relationship between metabolic risk factor clustering and cardiovascular mortality stratified by high blood glucose and obesity: NIPPON DATA90, 19902000. Diabetes Care 30: 1533-1538, 2007.

21. Kokubo Y, Okamura T, Yoshimasa Y, et al. Impact of metabolic syndrome components on the incidence of cardiovascular disease in a general urban Japanese population: the suita study. Hypertens Res 31: 2027-2035, 2008.

22. Noda H, Iso H, Saito I, Konishi M, Inoue M, Tsugane S. The impact of the metabolic syndrome and its components on the incidence of ischemic heart disease and stroke: the Japan public health center-based study. Hypertens Res 32: 289-298, 2009.

23. The DECODE Study Group. Does the constellation of risk factors with and without abdominal adiposity associate with different cardiovascular mortality risk? Int J Obes (Lond) 32: 757-762, 2008.

24. Lee J, Ma S, Heng D, et al. Should central obesity be an optional or essential component of the metabolic syndrome? Ischemic heart disease risk in the Singapore Cardiovascular Cohort Study. Diabetes Care 30: 343-347, 2007.

25. Tong PC, Kong AP, So WY, et al. The usefulness of the International Diabetes Federation and the National Cholesterol Education Program's Adult Treatment Panel III definitions of the metabolic syndrome in predicting coronary heart disease in subjects with type 2 diabetes. Diabetes Care 30: 1206-1211, 2007.

26. Kawamoto R, Ohtsuka N, Ninomiya D, Nakamura S. Carotid atherosclerosis in normal-weight metabolic syndrome. Intern Med 46: 1771-1777, 2007.

27. The Industrial Safety and Health Law and its Ordinances in Japan. [Internet]. [cited 2014 Jan 24]. Available from http://www.jniosh.g o.jp/icpro/jicosh-old/english/law/IndustrialSafetyHealth_Ordinance/ index.html

28. Wedeen RP. Occupational and environmental renal disease. Semin Nephrol 17: 46-53, 1997.

29. The Ministry of Health, Labour and Welfare, Ministry of Educa- tion, Culture, Sports, Science and Technology. Ethical Guidelines for Epidemiological Research, 2008. [Internet]. [cited 2013 July 28]. Available from: http://www.lifescience.mext.go.jp/files/pdf/37_ 139.pdf. (In Japanese).

30. Examination Committee of Criteria for "Obesity Disease" in Japan JSftSoO. New criteria for 'obesity disease' in Japan. Circ J 66: 987-992, 2002.

31. World Health Organization, International Association for the Study of Obesity, International Obesity Task Force. The Asia-Pacific Perspective: Redefining obesity and its treatment. Sydney: Health Communications, 2000. [Internet]. [cited 2013 Dec 6]. Available from: http://www.wpro.who.int/nutrition/documents/docs/Redefinin gobesity.pdf

32. Matsuo S, Imai E, Horio M, et al. Revised equations for estimated GFR from serum creatinine in Japan. Am J Kidney Dis 53: 982992, 2009.

33. Karelis AD, St-Pierre DH, Conus F, Rabasa-Lhoret R, Poehlman ET. Metabolic and body composition factors in subgroups of obesity: what do we know? J Clin Endocrinol Metab 89: 2569-2575, 2004.

34. Hildrum B, Mykletun A, Hole T, Midthjell K, Dahl AA. Agespecific prevalence of the metabolic syndrome defined by the International Diabetes Federation and the National Cholesterol Education Program: the Norwegian HUNT 2 study. BMC Public Health 7: 220, 2007.

35. Yoon YS, Lee ES, Park C, Lee S, Oh SW. The new definition of metabolic syndrome by the international diabetes federation is less likely to identify metabolically abnormal but non-obese individuals than the definition by the revised national cholesterol education program: the Korea NHANES study. Int J Obes (Lond) 31: 528-534, 2007.

36. Moy FM, Bulgiba A. The modified NCEP ATP III criteria maybe better than the IDF criteria in diagnosing Metabolic Syndrome among Malays in Kuala Lumpur. BMC Public Health 10: 678, 2010.

37. Thomas G, Sehgal AR, Kashyap SR, Srinivas TR, Kirwan JP, Navaneethan SD. Metabolic syndrome and kidney disease: a systematic review and meta-analysis. Clin J Am Soc Nephrol 6: 2364-2373, 2011.

38. Chagnac A, Weinstein T, Herman M, Hirsh J, Gafter U, Ori Y. The effects of weight loss on renal function in patients with severe obesity. J Am Soc Nephrol 14: 1480-1486, 2003.

39. Oda E. Multiple metabolic risk factors per se are more important than anthropometric cutoff points to predict morbid effects of obesity. Intern Med 49: 2653, 2010.

(C) 2015 The Japanese Society of Internal Medicine http://www.naika.or.jp/imonline/index.html 